companies. The abstract was a collaborative effort between Corrona and Novartis, with financial support provided by Novartis.

Table 1. Demographics, Treatment Profiles, Disease Activity, Quality of Life, and Work Productivity at Enrollment for Patients With Multidomain vs Single-Domain PsA Disease Presentations

\begin{tabular}{|c|c|c|c|}
\hline Characteristic* & $\begin{array}{l}\text { Multidomain } \\
(\mathrm{N}=1698)\end{array}$ & $\begin{array}{l}\text { Single Domain }{ }^{\dagger} \\
(N=617)\end{array}$ & $P$ Value $^{t}$ \\
\hline Age, years & $53.5(13.2)[1678]$ & $54.5(12.9)[607]$ & 0.20 \\
\hline Female, $\mathrm{n} / \mathrm{m}(\%)$ & $907 / 1689(53.7)$ & $314 / 610(51.5)$ & 0.35 \\
\hline Race, n (\%) & $n=1655$ & $n=596$ & 0.04 \\
\hline White & $1548(93.5)$ & $572(96.0)$ & \\
\hline Black & $9(0.5)$ & $4(0.7)$ & \\
\hline Other & $98(5.9)$ & $20(3.4)$ & \\
\hline $\mathrm{BMI}, \mathrm{kg} / \mathrm{m}^{2}$ & $32.0(7.4)[1658]$ & $31.3(7.6)[600]$ & $<0.01$ \\
\hline Symptom duration, years & $11.3(10.7)[1651]$ & $11.0(9.7)[594]$ & 0.51 \\
\hline Disease duration, years & $7.7(8.8)[1662]$ & $8.5(8.1)[598]$ & $<0.01$ \\
\hline \multicolumn{4}{|l|}{ Select comorbidities, n (\%) } \\
\hline Psoriasis & $1537(90.5)$ & $520(84.3)$ & $<0.01$ \\
\hline Nail psoriasis & $602(35.5)$ & $81(13.1)$ & $<0.01$ \\
\hline Depression & $280(16.5)$ & $57(9.2)$ & $<0.01$ \\
\hline Fibromyalgia & $114(6.7)$ & $23(3.7)$ & $<0.01$ \\
\hline Anxiety & $65(3.8)$ & $12(1.9)$ & 0.03 \\
\hline History of biologic use, $\mathrm{n}(\%)$ & $561(33.0)$ & $151(24.5)$ & $<0.01$ \\
\hline History of csDMARD use, $n(\%)$ & $478(28.2)$ & $151(24.5)$ & 0.08 \\
\hline History of prednisone use, $n(\%)$ & $230(13.5)$ & $83(13.5)$ & 0.95 \\
\hline Current biologic use, $n(\%)$ & $980(57.7)$ & $378(61.3)$ & 0.13 \\
\hline Current csDMARD use, $\mathrm{n}(\%)$ & $859(50.6)$ & $339(54.9)$ & 0.06 \\
\hline Current prednisone use, $\mathrm{n}(\%)$ & $122(7.2)$ & $42(6.8)$ & 0.75 \\
\hline Physician global assessment (VAS 0-100) & $24.3(21.4)[1686]$ & $10.9(15.0)[612]$ & $<0.01$ \\
\hline $\begin{array}{l}\text { Physician global assessment of psoriasis } \\
\text { (VAS } 0-100 \text { ) }\end{array}$ & $28.0(22.6)$ [1661] & $12.9(15.0)[594]$ & $<0.01$ \\
\hline Patient pain (VAS 0-100) & $44.8(29.2)[1590]$ & $28.6(26.9)[580]$ & $<0.01$ \\
\hline Patient-reported fatigue (VAS 0-100) & $45.9(29.2)[1676]$ & $33.8(28.4)[602]$ & $<0.01$ \\
\hline Patient global assessment (VAS 0-100) & $43.1(28.4)[1669]$ & $36.8(31.5)[605]$ & $<0.01$ \\
\hline HAQ-DI $(0-3)$ & $0.8(0.7)[1600]$ & $0.5(0.6)[586]$ & $<0.01$ \\
\hline$E Q-5 D(0-1)$ & $0.7(0.2)[1592]$ & $0.8(0.2)[579]$ & $<0.01$ \\
\hline EQ VAS $(0-100)$ & $67.4(21.5)[1667]$ & $75.5(19.8)[606]$ & $<0.01$ \\
\hline \multicolumn{4}{|l|}{ WPAI domains } \\
\hline Current employment, $\mathrm{n} / \mathrm{m}(\%)$ & $987 / 1646(60.0)$ & $381 / 595(64.0)$ & 0.08 \\
\hline$\%$ Work time missed & $6.2(17.5)[842]$ & $2.7(11.3)[323]$ & $<0.01$ \\
\hline$\%$ Impairment while working & $22.9(24.4)[887]$ & $12.4(18.9)[344]$ & $<0.01$ \\
\hline$\%$ Overall work impairment & $26.2(26.8)[798]$ & $13.0(19.5)[306]$ & $<0.01$ \\
\hline & & & \\
\hline \multicolumn{4}{|c|}{ 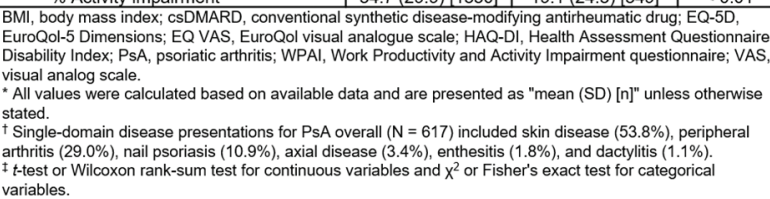 } \\
\hline
\end{tabular}

Table 2. Multidomain vs Single-Domain Impact on Outcomes-Multivariable Regression Selected PsA Disease Activity, Quality of Life, and Work Productivity and Activity Measures Relative to Single-Domain Presentations in Patients With PSA

\begin{tabular}{|c|c|c|}
\hline Outcomes* ${ }^{*}$ & $\begin{array}{c}\beta \text { Coefficient } \\
(95 \% \mathrm{Cl})\end{array}$ & $P$ Value \\
\hline Physician global assessment & $12.16(10.30,14.01)$ & $<0.001$ \\
\hline Physician global assessment of psoriasis & $14.03(12.03,16.04)$ & $<0.001$ \\
\hline Patient pain & $14.02(11.26,16.78)$ & $<0.001$ \\
\hline Patient-reported fatigue & $10.09(7.38,12.81)$ & $<0.001$ \\
\hline Patient global assessment & $5.65(2.81,8.49)$ & $<0.001$ \\
\hline HAQ-DI & $0.26(0.20,0.32)$ & $<0.001$ \\
\hline EQ-5D & $-0.07(-0.09,-0.06)$ & $<0.001$ \\
\hline \% Work time missed & $2.71(0.57,4.84)$ & 0.013 \\
\hline \% Impairment while working & $8.63(5.72,11.55)$ & $<0.001$ \\
\hline \% Overall work impairment & $11.02(7.69,14.36)$ & $<0.001$ \\
\hline$\%$ Activity impairment & $13.47(10.65,16.29)$ & $<0.001$ \\
\hline
\end{tabular}

Disclosure of Interests: Alexis Ogdie Grant/research support from: (To my university) Novartis, Pfizer, Grant/research support from: Novartis, Pfizer, Grant/research support from: Novartis, Pfizer, Grant/research support from: Novartis, Pfizer, Consultant for: AbbVie, Bristol-Myers Squibb, Celgene, Corrona, Eli Lilly and Company, Novartis, Pfizer, and Takeda, Consultant for: AbbVie, Amgen, Bristol-Myers Squibb, Celgene, Corrona, Eli Lilly, Novartis, Pfizer Inc, Takeda, Consultant for: Abbvie, Amgen, BMS, Celgene, Corrona, Lilly, Novartis, Pfizer, Takeda, Consultant for: Abbvie, Amgen, BMS, Celgene, Corrona, Lilly, Novartis, Pfizer, Takeda, Peter Hur Employee of: Peter Hur is an employee of Novartis Pharmaceuticals Corporation, East Hanover, New Jersey, USA, Mei Liu Employee of: M. Liu is an employee of Corrona, LLC., Sabrina Rebello Employee of: Corrona, LLC, Robert McLean: None declared, Blessing Dube Employee of: B. Dube is an employee of Corrona, LLC., Meghan Glynn Employee of: M. Glynn is an employee of Corrona, LLC., Philip J Mease Grant/research support from: AbbVie, Amgen, BMS, Celgene, Janssen, Lilly, Novartis, Pfizer, SUN and UCB, Consultant for: AbbVie, Amgen, BMS, Galapagos, Gilead Sciences, Inc., Janssen, Lilly, Novartis, Pfizer, SUN and UCB, Speakers bureau: AbbVie, Amgen, BMS, Celgene, Genentech, Janssen, Lilly, Novartis, Pfizer and UCB
DOI: 10.1136/annrheumdis-2019-eular.1069

\section{FRI0461 GENETIC ANALYSIS OF THE NF-KB PATHWAY CAN BE USEFUL TO DISTINGUISH PATIENTS AT RISK OF PSORIATIC ARTHRITIS WITHIN THE SPECTRUM OF PSORIATIC DISEASE}

Rubén Queiró Silva ${ }^{1}$, Pablo Coto-Segura ${ }^{2}$, Leire González-Lara ${ }^{3}$, Belen Alonso ${ }^{3}$, Juan Gómez ${ }^{3}$, Elías Cuesta-Llavona ${ }^{3}$, Eliecer Coto ${ }^{3} .{ }^{1}$ Hospital Universitario Central de Asturias, Rheumatology, Oviedo, Spain; ${ }^{2}$ Hospital Alvarez Buylla, Dermatology, Mieres, Spain; ${ }^{3}$ Hospital Universitario Central de Asturias, Genética Molecular, Oviedo, Spain

Background: Psoriasis and psoriatic arthritis (PsA) are the main manifestations of what is now known as psoriatic disease. Both entities share common genetic pathways, but they also differ. The NF-Kb pathway has been implicated in the genesis of psoriatic disease, but the differential contribution of this genetic pathway to the risk of psoriasis and PsA is not fully understood ${ }^{1}$.

Objectives: Our aim was to study the association of common polymorphisms at genes of the NF-Kb pathway in patients with psoriatic disease. Methods: The study involved a total of 690 psoriatic disease patients (187 of them with PsA) and 550 controls. We genotyped three common polymorphisms in NFKB1 (rs230526), NFKBIA (rs7152376) and NFKBIZ (rs3217713 indel) and compared allele and genotype frequencies between cases and controls.

Results: The rare NFKBIA rs7152376 C was significantly more frequent in the PsA group vs. controls (0.42 vs. $0.36 ; p=0.04, O R=1.29,95 \%$ $\mathrm{Cl}=1.02-1.63)$. Compared to skin psoriasis, PsA patients showed a significantly higher frequency of the rs7152376 C $(0.42$ vs. $0.31 ; p<0.001)$. In reference to the genotypes, carriers of rs7152376 C (CC+CT) were nonsignificantly more frequent in PsA compared to controls (0.66 vs. 0.58; $p=0.06)$. However, the frequency of these carriers was significantly higher in PsA vs. skin psoriasis $(p=0.004)$. Thus, our data showed significant association between the rare NFKBIA rs7152376 C allele and PsA, and a trend toward the opposite effect for skin psoriasis. Neither NFKB1 rs230526 or NFKBIZ rs3217713 indel were associated with the risk of developing psoriasis or PsA.

Conclusion: We found a significant association between NFKBIA variants and PsA. Our study shows that alterations in the same genetic pathway may have differential effects on different manifestations of psoriatic disease. Additional studies from larger cohorts and different populations are necessary to validate these results.

\section{REFERENCES:}

[1] Nair RP, Duffin KC, Helms C, et al. Genome-wide scan reveals association of psoriasis with IL-23 and NF-kappaB pathways. Nat Genet 2009; 41 199-204.

Disclosure of Interests: None declared DOI: 10.1136/annrheumdis-2019-eular.3782

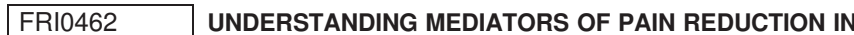 PSORIATIC ARTHRITIS PATIENTS TREATED WITH TOFACITINIB: ROLE OF INFLAMMATION}

Peter C. Taylor ${ }^{1}$, Philip J. Mease ${ }^{2}$, Andrew G. Bushmakin ${ }^{3}$, Joseph C. Cappelleri ${ }^{3}$, Roy Fleischmann ${ }^{4}$, Lara Fallon ${ }^{5}$, John Woolcott ${ }^{6}$, Alexis Ogdie ${ }^{7}$, Valderilio F. Azevedo ${ }^{8}$, Kurt de Vlam ${ }^{9} .{ }^{1}$ University of Oxford, Oxford, United Kingdom;

${ }^{2}$ Swedish Medical Center and University of Washington, Seattle, WA, United States of America; ${ }^{3}$ Pfizer Inc, Groton, CT, United States of America; ${ }^{4}$ Metroplex Clinical Research Center and University of Texas Southwestern Medical Center, Dallas, TX, United States of America; ${ }^{5}$ Pfizer Inc, Montreal, QC, Canada; ${ }^{6}$ Pfizer Inc, Collegeville, PA, United States of America; ${ }^{7}$ Perelman School of Medicine at the University of Pennsylvania, Philadelphia, PA, United States of America; ${ }^{8}$ Universidade Federal do Paraná, Curitiba, Brazil; ${ }^{9}$ Department of Rheumatology, University Hospitals Leuven, Leuven, Belgium

Background: Pain is a priority for patients (pts) with psoriatic arthritis (PsA) and physicians. Tofacitinib is an oral Janus kinase inhibitor for the treatment of PsA. As pain is a multidimensional phenomenon, there is growing interest in understanding mechanisms of pain relief during treatment.

Objectives: To examine the potential role of inflammation in the effect of tofacitinib on pain in pts with PsA, using mediation modelling.

Methods: Data were from the Phase 3 OPAL Broaden (NCT01877668) and OPAL Beyond (NCT01882439) studies of pts with active PsA treated 